\title{
Science, Gender, and the Emergence of Depression in American Psychiatry, I952-I980
}

\author{
LAURA D. HIRSHBEIN *
}

Abstract. Between the first (I952) and the third (I980) editions of psychiatry's Diagnostic and Statistical Manual of Mental Disorders, depression emerged as a specific disease category with concrete criteria. In this article, I analyze this change over time in psychiatric theory and diagnosis through an examination of medication trials and category formation. Throughout, I pay particular attention to the ways in which psychiatrists and researchers invoked science in their clinical trials and disease theories, as well as the ways in which gender played an important but largely unspoken role in the formation of a category of depression. KEYWORDS: depression, melancholia, psychiatry, neurology, gender, nosology.

I 1975, Robert Woodruff, a prominent psychiatric researcher from Washington University in St. Louis, asked the question "Is Everyone Depressed?" Woodruff and his colleagues noted that depression seemed to be everywhere, and they seriously assessed the possibility of widespread psychiatric disease by surveying relatives of depressed, hospitalized patients to see if the relatives were depressed. As it turned out, the relatives were not generally depressed, and so Woodruff and his group concluded that, "If 'the mass of men lead lives of quiet desperation,' that despair is to be seen as philosophical, economic, or existentialnot psychiatric in our sense. We believe the distinction is important and that failure to appreciate it has been a constant source of

\footnotetext{
* University of Michigan Department of Psychiatry, 9C UH 9I5I, I500 E. Medical Center Dr., Ann Arbor, MI 48I09. Email: lauradh@umich.edu.

JOURNAL OF THE HISTORY OF MEDICINE AND ALLIED SCIENCES

(C) The Author 2006. Published by Oxford University Press. All rights reserved.

For permissions, please e-mail: journals.permissions@oxfordjournals.org doi:I0.I093/jhmas/jrjo37
} 
confusion for psychiatrists." ${ }^{1}$ Although Woodruff concluded that psychiatric illness was not as widespread as it appeared, the fact that he and his group engaged with this question at all is evidence of the depth to which ideas about depression had penetrated American psychiatry and society.

Yet while depression had become a widely discussed problem in the I970s, it had barely appeared in the medical literature only two decades before, and it was not mentioned as a specific entity in the American Psychiatric Association's 1952 nosology, the Diagnostic and Statistical Manual (DSM-I). ${ }^{2}$ Depression was sometimes described as a symptom of a variety of ailments (from neurasthenia to manicdepressive psychosis) prior to the I950s and I960s, but it was not granted the status of a diagnostic category until the third edition of the Diagnostic and Statistical Manual (DSM-III), in I980. ${ }^{3}$ Further, in the years prior to the introduction of specific psychiatric medications in the I950s, medical authors noted that patients who appeared depressed responded to electroconvulsive therapy (ECT); however, the use of ECT did not define patients as depressed. ${ }^{4}$

Although there were certainly descriptions of melancholia in physicians' writings throughout human history, I argue that depression as the illness that we know it now is a twentieth-century phenomenon that incorporates assumptions about gender, profession, and

I. Robert A. Woodruff, Jr., Paula Clayton, and Samuel B. Guze, "Is Everyone Depressed?," Am. J. Psychiatry, I975, 132, 627-28.

2. American Psychiatric Association, Diagnostic and Statistical Manual: Mental Disorders (Washington, D.C.: American Psychiatric Association, I952). For an excellent analysis of the emergence of DSM-I, see Gerald N. Grob, "Origins of DSM-I: A Study in Appearance and Reality," Am.J. Psychiatry, I99I, 148, 42 I-30.

3. American Psychiatric Association, Diagnostic and Statistical Manual of Mental Disorders, 3rd ed. (Washington, D.C.: American Psychiatric Association, I980). On ways in which depression as a symptom appeared in the medical literature, see for example John Madison Taylor, "Climate or Environment as a Factor in the Repair of Neurasthenia and Melancholia," Boston Med. Surg. J., I 897, 137, 4I 5-I6; Smith Ely Jelliffe and William A. White, "The Psychoneuroses and Actual Neuroses," in Diseases of the Nervous System: A Text-Book of Neurology and Psychiatry (Philadelphia: Lea \& Febiger, I9I 5), 593-63 I; Henry M. Swift, "The Progress of Recurrent Insanity of the Manic Depressive Type," Am. J. Insanity, I907, 64, 3 I I -26 .

4. See for example Lothar B. Kalinowsky and Paul H. Hoch, Shock Treatments and Other Somatic Procedures in Psychiatry (New York: Grune \& Stratton, I946); Max Fink, "EST: A Special Case in Pharmacotherapy," in Phenomenology and Treatment of Depression, ed. William E. Fann et al. (New York: Spectrum Publications, 1977), 285-94. One author in I960 did ascribe to ECT the role of the intervention that began "The era of the modern treatment of depressive disorders" (starting with the Italian team of Cerletti and Bini in the late I930s). Fritz A. Freyhan, "The Modern Treatment of Depressive Disorders," Am. J. Psychiatry, I960, 116, I057-64. 
science. ${ }^{5}$ Depression is a disease, like other diseases, that is framed by its social, cultural, professional, and gender contexts. ${ }^{6}$ To understand the current role of depression as a major focus of psychiatric attention requires historical attention to the social and cultural context of disease conceptions, as well as changes in psychiatry, over this time period. $^{7}$

As historian and psychopharmacologist David Healy has persuasively argued, the introduction of medications in the I950s and I960s resulted in the concept of a specific disease of depression. Through the studies of medications on psychiatric patients, medications that seemed to work on patients who appeared to be depressed were labeled "antidepressants," while patients who responded to antidepressants were in turn diagnosed with depression. ${ }^{8}$ In this article, I use Healy's argument as a place to begin in order to analyze more closely the American psychiatric context, particularly in light of Harry Marks's observations about the changing nature and practice of clinical research in the twentieth century. ${ }^{9}$ Further, I use the insights of historians of gender to examine the construction of depression as a disease of women. ${ }^{10}$

5. On earlier physician descriptions of melancholia, see Stanley W. Jackson, Melancholia and Depression: From Hippocratic Times to Modern Times (New Haven, Conn.: Yale University Press, I986). For other descriptions of depression over the centuries, see Jennifer Radden, ed., The Nature of Melancholy: From Aristotle to Kristeva (New York: Oxford University Press, 2000). Berrios and Porter have provided a good overview on this topic in the nineteenth and twentieth centuries in the United States and Great Britain. See German E. Berrios, "Mood Disorders: Clinical Section," and Roy Porter, "Mood Disorders: Social Section," in A History of Clinical Psychiatry: The Origin and History of Psychiatric Disorders, ed. German E. Berrios and Roy Porter (New York: New York University Press, I995), 384-408, 409-20.

6. Charles E. Rosenberg and Janet Golden, eds., Framing Disease: Studies in Cultural History (New Brunswick, N.J.: Rutgers University Press, I992).

7. For an unsurpassed overview of the history of American psychiatry, see Gerald Grob's series of volumes: Mental Institutions in America: Social Policy to 1875 (New York: Free Press, 1973); Mental Illness and American Society, 1875-1940 (Princeton, N.J.: Princeton University Press, I983); From Asylum to Community: Mental Health Policy in Modern America (Princeton, N.J.: Princeton University Press, I99I).

8. David Healy, The Antidepressant Era (Cambridge, Mass.: Harvard University Press, 1997).

9. Harry M. Marks, The Progress of Experiment: Science and Therapeutic Reform in the United States, 1900-1990 (New York: Cambridge University Press, I997).

Io. Joan W. Scott, "Gender: A Useful Category of Historical Analysis," Am. Hist. Rev., 1986, 91, I053-75; Peter G. Filene, Him/Her/Self: Sex Roles in Modern America, 2nd ed. (Baltimore, Md.: Johns Hopkins University Press, 1986). For additional work on the history of women and mental illness, as well as critiques of mainstream psychiatry, see Nancy Tomes, "Historical Perspectives on Women and Mental Illness," in Women, Health, and Medicine in America, ed. Rima D. Apple (New York: Garland Publishing, Inc., I990), I43-72; Tomes, "Feminist Histories of Psychiatry," in Discovering the History of Psychiatry, ed. Mark S. Micale and Roy Porter (New York: Oxford University Press, I994), 348-83. 
This article describes the changes that occurred between DSM-I and the emergence of a specific category of depression as it appeared in DSM-III less than three decades later. Over a very brief period of time, depression became crystallized as a clear diagnostic entity with specific therapies and a possible biological mechanism. In the process, a vocal number of psychiatrists made increasing arguments about the need to make the specialty more scientific and placed evolving psychiatric diagnoses at the center of that project. In this article, I analyze clinical trials of psychiatric medications and theories about depression in published medical sources. ${ }^{11}$ I will briefly review the state of depressive symptoms in psychiatric diagnosis in the first half of the twentieth century and then describe the beginning of medication trials in psychiatric hospital patients in the I950s. I will then move on to discuss psychiatrists' increasing calls for using scientific methods to perform clinical trials in the I960s and I970s. Finally, I will explore the changes in how psychiatrists described depression and transformed clinical observation into formalized diagnostic criteria. Throughout, I will pay particular attention to the ways in which patients' sex and psychiatrists' expectations about gender played a largely unspoken but important role in the formation of a diagnosis of depression.

\section{MELANCHOLIA IN THE EARLY 2OTH CENTURY}

In the first third of the twentieth century, symptoms of what would now be identified as depression were included within two major classes of disorders, psychoses and neuroses, and two different medical specialties, psychiatry and neurology. For psychiatrists, depressive symptoms were part of the broad spectrum of manic-depressive psychosis, a form of insanity that they frequently encountered in psychiatric institutions. ${ }^{12}$

I I. I located the primary source articles in three ways: first, I reviewed the whole time period in the Am. J. Psychiatry; second, I reviewed articles from this time period that had been cited by currently well-accepted articles in the field of depression studies; and third, I used Medline (the medical database) to find other sources on clinical research and diagnosis in depression in this time period.

I2. Manic-depressive psychosis was differentiated from dementia praecox (or schizophrenia) by clinical course: patients with manic-depressive psychosis had a waxing and waning presentation of symptoms, while patients with dementia praecox seemed to primarily decline. See William A. White, Outlines of Psychiatry (New York: The Journal of Nervous and Mental Disease Publishing Company, I907), pp. I08-24. 
For neurologists, depressive symptoms were most commonly part of a neurosis (sometimes specifically identified with neurasthenia) that they might encounter in office-based outpatient practice. ${ }^{13}$ By the I940s, patients' depressive symptoms were being treated by psychiatrists in both offices and hospitals (neurologists had for the most part distanced themselves from mental symptoms). ${ }^{14}$

While depressive symptoms were part of several diagnoses, the specific problem of depression was not a focus of psychiatric attention in the first half of the twentieth century. Further, during that time period, psychiatric entities were by no means well defined. Many medical writers of the time insisted that, since only symptoms and not etiology were known about varieties of insanity, it was premature to attempt a classification system. ${ }^{15}$ Psychiatrists did produce two classification systems in this time period, one in I9I 8 and one in I933, and both were an uncomfortable mix of etiological and symptom-based categories. In neither classification did depression exist as a separate entity. ${ }^{16}$

By the I930s, one form of depression did capture some psychiatric attention: involutional melancholia. In the first several editions of his nosological work in the late nineteenth century, the German psychiatrist Emil Kraepelin had suggested that involutional melancholia was a separate disease and should not be classified with manic-depressive insanity. In the early twentieth-century editions of his nosology,

I3. See for example Francis X. Dercum, Rest, Suggestion and Other Therapeutic Measures in Nervous and Mental Diseases, 2nd ed. (Philadelphia: P. Blakiston's Son \& Co., I9I7), pp. 2 I $2-24$.

I4. Andrew Abbott has argued that psychiatry and neurology split in the I920s, with a psychiatric focus on the psychoanalytic and a neurological focus on the organic. See Andrew Delano Abbott, "The Emergence of American Psychiatry, I880-I930" (Ph.D. diss., University of Chicago, I982); Abbott, The System of Professions: An Essay on the Division of Expert Labor (Chicago: University of Chicago Press, I988), pp. 280-3 I 4 .

I 5. See for example Clarence B. Farrar, "On the Methods of Later Psychiatry," Am. J. Insanity, I905, 61, 437-66; Lewellys F. Barker, "The Relations of Internal Medicine to Psychiatry," Am. J. Psychiatry, I9I4, 71, I3-28; H. A. Tomlinson, "The Unity of Insanity," Am. J. Psychiatry, I906, 63, I55-66.

I6. Committee on Statistics of the American Medico-Psychological Association and Bureau of Statistics of the National Committee for Mental Hygiene, Statistical Manual for the Use of Institutions for the Insane (New York: National Committee for Mental Hygiene, I9I8); H. B. Logie, ed., A Standard Classified Nomenclature of Disease (New York: The Commonwealth Fund, I933). For examples of how these classification systems were used, see Horatio M. Pollock, "The Future of Mental Disease from a Statistical Viewpoint," Am. J. Psychiatry, I924, 80, 423-34; Neil A. Dayton, "The First Year of the New Standard Nomenclature of Diseases in Massachusetts Mental Hospitals," Am. J. Psychiatry, I935, 92, 589-613. See also Gerald N. Grob, "Origins of DSM-I," Am. J. Psychiatry, I99I, 148, 42 I-30. 
however, Kraepelin bowed to the suggestions of others that it was simply a form of insanity. ${ }^{17}$ In the first several decades of the twentieth century, most authors followed Kraepelin's lead in classifying all of melancholia as part of manic-depressive insanity. But the idea of a phenomenon of depression in later life, a depression that looked different from that associated with manic-depressive insanity, lingered and became more common by the I930s. ${ }^{18} \mathrm{~A}$ number of therapies were proposed for involutional melancholia by the late I930s and I940s, particularly shock therapies (including insulin, metrazol, and electric shock). Psychiatrists became increasingly enthusiastic about the use of aggressive therapies in involutional melancholia (at the same time that enthusiasm for interventions such as electroconvulsive therapy [ECT] for schizophrenia began to wane).$^{19}$ By the I950s, patients with involutional melancholia were generally included with patients with manic-depressive psychosis in medication trials. ${ }^{20}$

At the time when medications were introduced into psychiatric practice, patients were not routinely given specific psychiatric diagnoses. If patients were classified at all, they generally fell into one of the two main classes of disorders, dementia praecox (schizophrenia) or manic-depressive psychosis. Although some psychiatrists of the time might have attempted to understand the unconscious conflicts that drove their patients to the point of insanity, psychiatrists who cared for hospitalized patients put their treatment emphasis on behavior. They did not have specific measures by which to judge clinical improvement, but psychiatrists in the first half of the century typically used discharge and readmission information to gauge the success of their interventions.

I7. Jackson, Melancholia and Depression, pp. 207-I I.

I8. Swift, "The Prognosis of Recurrent Insanity of the Manic Depressive Type." For a general overview of involutional melancholia, see D. K. Henderson, "Affective Reaction Types: II-Involutional Melancholia," in A Text-Book of Psychiatry for Students and Practitioners, 3rd ed. (Oxford: Oxford University Press, I933), pp. I60-83.

I9. See for example Purcell G. Schube et al., "Involutional Melancholia: Treatment with Theelin," Arch. Neurol. Psychiatry, I937, 38, 505-I2; C. C. Ault, Emmett F. Hoctor, and August A. Werner, "Theelin Therapy in the Psychoses," J. Am. Med. Assoc., I937, 109, I786-88; A. E. Bennett, "Metrazol Convulsive Shock Therapy in Affective Psychoses," Am. J. Med. Sci., I939, 198, 695-701.

20. By the late I960s, researchers were identifying the old diagnosis of involutional melancholia as quaint, and the specific diagnosis disappeared. See for example Saul H. Rosenthal, "The Involutional Depressive Syndrome," Am. J. Psychiatry, I968, 11 Suppl., $2 \mathrm{I}-35$. 


\section{MEDICATION TRIALS IN THE I95OS}

In the early I950s in the United States and in Europe, physicians began to work in collaboration with pharmaceutical companies to test a wide range of medications on a variety of patients. ${ }^{21}$ As Healy has described, pharmaceutical companies also worked with physicians who were employed in mental hospitals to test their products there. ${ }^{22}$ As Gerald Grob has pointed out, the hospital environment for psychiatric patients at mid-century could be chaotic, with disordered persons and overcrowded conditions. ${ }^{23}$ In this setting, psychiatrists who used the new medications measured success by whether the patients appeared to be improved, particularly in measures such as the lessened need for ECT or whether the patients could be advanced toward discharge. ${ }^{24}$

The initial clinical trials of psychiatric medication frequently involved administering medications to a wide population of hospitalized patients and observing the results. In the I950s, medications were not specifically designated for patients with particular diagnoses; indeed, chlorpromazine (Thorazine), which has become widely known as a medication for schizophrenia, was tested with

2I. On the history of the pharmaceutical industry and its relationship to medicine, see Jonathan Liebenau, Medical Science and Medical Industry: The Formation of the American Pharmaceutical Industry (Baltimore, Md.: Johns Hopkins University Press, I987); Louis Galambos and Jane Eliot Sewell, Networks of Innovation: Vaccine Development at Merck, Sharp \& Dohme, and Mulford, 1895-1995 (New York: Cambridge University Press, I995). While this relationship is currently seen as extremely problematic (see for example David Healy, Let Them Eat Prozac: The Unhealthy Relationship between the Pharmaceutical Industry and Depression [New York: New York University Press, 2004]), the nature of the relationship of pharmaceutical companies to physicians in the middle of the twentieth century bears further investigation.

22. Healy, The Antidepressant Era.

23. Gerald N. Grob, The Mad Among Us: A History of the Care of America's Mentally Ill (Cambridge, Mass.: Harvard University Press, I994).

24. During this time period, ECT was accepted by virtually all the authors in the psychiatric literature as the definitive treatment for a variety of ailments. The success of medication in helping patients to avoid ECT was frequently mentioned in the I95OS and I960s. See for example Benjamin Pollock, "Clinical Findings in the Use of Tofranil in Depressive and Other Psychiatric States," Am. J. Psychiatry, I959, 116, 3I2-I7; David C. English, "A Comparative Study of Antidepressants in Balanced Therapy," Am. J. Psychiatry, I96I, 117, 865-72; William A. Horwitz, "Physiological Responses as Prognostic Guides in the Use of Antidepressant Drugs," Am. J. Psychiatry, I968, 125, 60-68. On the importance of discharge from the hospital as an outcome measure in this time period, see William F. Orr et al., "Factors Influencing Discharge of Female Patients from a State Mental Hospital," Am. J. Psychiatry, I968, 111, 576-82. 
good effect on patients with depressive symptoms. ${ }^{25}$ The evidence that therapies were effective was generally provided through comments by the investigators that the patients had improved. ${ }^{26}$ During the I950s, most research in psychiatric medications did not have specific measures for efficacy. Researchers used very simple numbers to indicate percentages of patients who improved, but they also tended to use case reports to best illustrate the dramatic improvement in the lives of some of the patients who received medications. ${ }^{27}$ One of the first papers on the new antidepressant imipramine (which became the most widely known medication for depression over the next two decades) measured outcome by looking at changes in four areas (subjective comfort, ward management, ability to go home, and social effectiveness); however, improvement within each area was left to the researcher to define. ${ }^{28}$

In the I950s, a wide variety of psychiatrists published the results of clinical trials held during that period, from major figures at large research universities to private practitioners. In this time period, there were not major differences between the research methods of these different types of practitioners, nor was there agreement on the role of research in demonstrating clinical efficacy. Indeed, Theodore Robie, a private practitioner in New Jersey who administered iproniazid (trade name Marsalid) to large numbers of his patients, commented on the power of clinical experience (as compared with research investigation):

25. See for example Herman C. B. Denber and Etta G. Bird, "Chlorpromazine in the Treatment of Mental Illness. III: The Problem of Depression," Am. J. Psychiatry, I956, 112, IO2 I; Joseph A. Barsa and Nathan S. Kline, "Depression Treated with Chlorpromazine and Promethazine," Am. J. Psychiatry, I957, 113, 744-45. Another medication tried in this time period, orphenadrine, was also originally tested in Parkinsonism, found to have euphoric effects, and then tried in patients with depressive symptoms. Jonas B. Robitscher and Sydney E. Pulver, "Orphenadrine in the Treatment of Depression: A Preliminary Study," Am. J. Psychiatry, I958, 114, II3-I5.

26. See for example Antonio J. DeLiz Ferreira and Harry Freeman, "A Clinical Trial of Marsilid in Psychotic Depressed Patients," Am. J. Psychiatry, I958, 114, 933-34.

27. For an example of improvement in outpatients on an antidepressant "stimulating" agent, see Howard D. Fabing, J. Robert Hawkins, and James A. L. Moulton, "Clinical Studies on a-(2-Piperidyl) Benzhydrol Hydrochloride, a New Antidepressant Drug," Am. J. Psychiatry, I955, 111, 832-37.

28. H. Azima and R. H. Vispo, "Imipramine: A Potent New Anti-Depressant Compound," Am. J. Psychiatry, I958, 115, 245-46. Roland Kuhn, the researcher credited with the discovery of imipramine, summarized his research in Switzerland in his I958 review article, "The Treatment of Depressive States with G22355 (Imipramine Hydrochloride)," Am. J. Psychiatry, I958, 115, 459-64. 
During the I9 years that I have been giving ECT for melancholia, there have been many occasions when I have seen what appeared like a miracle as a severely depressed person emerged from despondency after a few treatments. But in the 33 years I have been practicing there has been no experience as satisfying as observing the occasional depressive who emerges from his despondency after a few days on Marsilid. To be sure there are very few that respond so quickly, but it is astounding to see when it does occur! It demonstrates more convincingly than any statement any researcher can make, what a remarkable chemical this is and how widespread will be its field of usefulness, once we have acquired the accurate methods of prescribing that are necessary to assure its safe application in each case. ${ }^{29}$

While researchers were providing interesting and important information for practitioners, authors in the professional literature continued to privilege clinical experience over research trials during this time period.

While both individual clinicians and investigative teams found medications helpful, they tended to describe medication efficacy in broad terms. What researchers did articulate clearly, however, was that medications such as imipramine helped in depressed patients. As New York practitioner Benjamin Pollack explained about imipramine in I959, "All research workers who used this drug initially were unanimous in the conclusion that, unlike many other psychopharmacological agents, it specifically affects depressive conditions and has very little effect on paranoid states or disturbed behavior, particularly in schizophrenics." ${ }^{30}$ But as researchers began to reflect on what it meant for a medication to help patients with depression, they began to articulate the problems with the concept of "depression" as it existed at that time. New Jersey neuropsychiatrist William Furst explained that there was much confusion about whether depression was a syndrome or a symptom, and that a real nosology of depression was needed. ${ }^{31}$

Although psychiatrists who were trying medications on patients in the I950s were frequently enthused about the possibilities of the

29. Theodore R. Robie, "Iproniazid Chemotherapy in Melancholia," Am. J. Psychiatry, I958, 115, 407 (italics added).

30. Pollock, "Clinical Findings in the Use of Tofranil in Depressive and Other Psychiatric States," 3 I 4.

3I. William Furst, "Therapeutic Re-Orientation in Some Depressive States: Clinical Evaluation of a New Mono-Amine Oxidase Inhibitor (W-I 544-a) (Phenelzine) (Nardil))," Am. J. Psychiatry, I959, 116, 429-34. 
medication, they generally did not provide extensive descriptions of their research methodology or its potential limitations. Without much comment, psychiatrists in private practice and in hospitals provided the number of patients included in the study, and they usually mentioned the source of the patients (i.e., hospital or outpatient clinics). While researchers during the I950s sometimes mentioned the diagnosis of patients (generally either manic-depressive psychosis or schizophrenia) and how they were included in the trial (e.g., consecutive admissions to the hospital), they never mentioned how much the patients knew about the trial or whether they had provided consent to be included. ${ }^{32}$

One major feature of these trials that was seldom discussed was the fact that, of the trials that provided information about the sex breakdown of the patients, the vast majority included a preponderance of female patients. ${ }^{33}$ Researchers frequently noted the number of patients in the trial and their breakdown by sex, but they did not comment on how this might affect the study or the conclusions drawn from the study. In later decades, researchers explained the continued predominance of women subjects by citing the greater prevalence of depression in women (as discussed below). In the I950s, however, patients were generally not selected for trials based on diagnosis. Instead, the large numbers of women in clinical trials appeared to be a reflection of the hospital population of the time. Some researchers explained this in the I960s and I970s by reporting that the hospital population had shifted by the I950s. They observed

32. The issue of consent and psychiatric treatment and research is a large and complicated one, and its history has not been fully explored. Turner in 1962 mentioned that, with the changing demographics of hospital populations by the I960s and the increasing number of voluntary patients, electroshock therapy declined because voluntary patients would not agree to it (William J. Turner, Francis J. O'Neill, and Sidney Merlis, "The Treatment of Depression in Hospitalized Patients before and since the Introduction of Antidepressant Drugs," Am. J. Psychiatry, I962, 119, 42 I-26). The first mention I could find of a researcher mentioning that patients signed an informed consent prior to participation in a clinical trial was Sidney Malitz and Maureen Kanzler, "Are Antidepressants Better than Placebo?," Am. J. Psychiatry, I97I, 127, I605-II. For a history of earlier human experimentation, see Susan E. Lederer, Subjected to Science: Human Experimentation in America before the Second World War (Baltimore, Md.: Johns Hopkins University Press, I995).

33. Denber and Bird, "Chlorpromazine in the Treatment of Mental Illness"; Barsa and Kline, "Depression Treated with Chlorpromazine and Promethazine"; Ferreira and Freeman, "A Clinical Trial of Marsilid in Psychotic Depressed Patients"; Wilson G. Scanlon and William M. White, "Iproniazid (Marsilid): Its Use in Office Treatment of Depression," Am.J. Psychiatry, I958, 114, I036-37; Azima and Vispo, "Imipramine"; Pollock, "Clinical Findings in the Use of Tofranil in Depressive and Other Psychiatric States." 
that more older men were in the hospital in the pre-World War II era, while by the I950s and I960s the hospital population had shifted toward younger, more neurotic women. Psychiatrists and others generally claimed that psychiatric treatments of older men had significantly improved (particularly with ECT) such that those men did not need the hospital anymore; therefore, the patients who were in the hospital were those most in need of treatment. ${ }^{34}$ While researchers in psychiatry did not make a particular issue over the larger number of women in these clinical trials, the practice in psychiatry research of the time was in striking contrast to the usual practice in other parts of medical research of including only men in clinical trials. ${ }^{35}$

\section{SCIENCE AND MEDICATION TRIALS}

By the I960s and I970s, more psychiatrists were invoking the ideas of science to try to change the ways in which medications were tried on patients. But, as Marks has pointed out in other areas of medicine during the same time period, this was by no means an even or unproblematic process. ${ }^{36}$ Although some aspects of psychiatrists' clinical trials were not questioned, other aspects of the trial design came under increasing scrutiny during this time period, and clinical trial protocols became more commonly designed with comparison

34. See for example Turner, O'Neill, and Merlis, "The Treatment of Depression in Hospitalized Patients"; Donald F. Klein and Max Fink, "Psychiatric Reaction Patterns to Imipramine," Am. J. Psychiatry, I962, 119, 432-38; Saul H. Rosenthal, "Changes in a Population of Hospitalized Patients with Affective Disorders, I945-1965," Am. J. Psychiatry, I966, 123, 67I-8I; Gerald L. Klerman and Eugene S. Paykel, "Depressive Pattern, Social Background, and Hospitalization," J. Nerv. Ment. Dis., I970, 150, 466-78.

35. As several researchers have pointed out, the vast majority of research on heart disease interventions was completed on samples of men and then extrapolated to women. In I990, the National Institutes of Health created an Office on Women to ensure that women were adequately represented in clinical trials. Joan L. Thomas and Patricia A. Braus, "Coronary Artery Disease in Women: A Historical Perspective," Arch. Intern. Med., I998, 158, 333-37; Kathryn M. King and Pauline Paul, "A Historical Review of the Depiction of Women in Cardiovascular Literature," West. J. Nurs. Res., I 996, 18, 89-I0I; Janet W. Rich-Edwards et al., "Medical Progress: The Primary Prevention of Coronary Heart Disease in Women," N. Engl. J. Med., I995, 332, I758-66; Teresa S. M. Tsang et al., "Risks of Coronary Heart Disease in Women: Current Understanding and Evolving Concepts," Mayo Clin. Proc., 2000, 75, I289-303; Christine L. Miller and Cynthia R. Kollauf, "Evolution of Information on Women and Heart Disease 1957-2000: A Review of Archival Records and Secular Literature," Heart Lung, 2002, 31, 253-6I; Joseph Palca, "Women Left Out at NIH," Science, I990, 248, I60 I-2; Ruth B. Merkatz et al., "Women in Clinical Trials of New Drugs," N. Engl. J. Med., I993, 329, 292-96.

36. Marks, The Progress of Experiment. 
groups between medications (and sometimes placebo). At the same time that investigators wanted to make sure that their interventions worked (through statistical analysis of samples of patients), they were also critiquing an older psychiatric tradition of the individual personality or case. While researchers in psychiatry attempted to demonstrate the value of specific therapeutics, their clinical trials led toward a re-imagining of psychiatric theory and practice by the I980s.

By the late I950s and early I960s, some researchers were beginning to question the research method of simply giving a hospitalized patient a medication to see if it worked. Some noted in particular that it was difficult to assess the effect of the drug, especially if the administering psychiatrist suggested to the patient that the drug would be helpful. ${ }^{37}$ In 1959, Erwin Linn, from the Laboratory of Socio-Environmental Studies at the National Institute of Mental Health, further pointed out that it was difficult to sort out the differences between primary and side effects or to interpret patients' reports of improvement. ${ }^{38}$

Although imipramine and iproniazid had been studied in some detail in the I950s, more medications became available in the I960s, including the monoamine oxidase inhibitors. Medication trials during the I960s were more likely to compare a number of agents (including some placebo response), although the researchers usually concluded that multiple medications worked and did not make much out of slight differences between medications. One typical example from this time period was a study of roo patients (62 women, 38 men) hospitalized in a state facility in Pennsylvania. The authors of the study randomly assigned patients to groups in order to compare response in symptoms to isocarboazid, nialamide, phenelzine, pheniprazine, and imipramine. The treating teams conducted symptom assessments before and after treatment and classified the patients into groups based on how many of the symptoms improved. Although these researchers

37. One Detroit researcher in 1958 explained that his trial of iproniazid did not involve the use of "sales talk" prior to giving the medication to his clinical subjects. Robert R. Schopbach, "Clinical Note Concerning Iproniazid (Marsilid)," Am. J. Psychiatry, I958, 114, 838-39.

38. Erwin L. Linn, "Sources of Uncertainty in Studies of Drugs Affecting Mood, Mentation or Activity," Am. J. Psychiatry, I959, 116, 97-I03. 
clearly worked to try to address potential issues in research methodology in their study, they made no claims to be using any specific scientific method or controlled trial. Indeed, they titled their study a "Collaborative Clinical Experience with Five Antidepressants." 39 So, although some researchers were becoming more systematic in their comparisons between drugs, clinical experience, not science, was the primary authority for drug trials in the early i96os.

Not only were medication studies more likely to include multiple agents, but also researchers of this time period were more likely to use multiple sites for their studies and to screen patients prior to admission to the study. For studies on medications that were becoming known as antidepressants, patients were screened for inclusion if they had depressive symptoms but excluded if they had other problems (such as alcoholism). In addition, electroshock therapy was sometimes used as a treatment within the comparison study (although researchers acknowledged that it was not possible to double-blind the group receiving shock treatments). ${ }^{40}$ Throughout these studies there was an explicit assumption that better research design (which would include at least some features of randomized, placebo-controlled trials) would yield better patient selection and better response to medication. For one researcher, the fact that his depressed sample of patients responded better to a medication for schizophrenia than they did to the antidepressant meant that his sample had not been properly diagnosed. $^{41}$

By the I970s, clinical trials of psychiatric treatments looked substantially different than the clinical trials only two decades before. ${ }^{42}$ Psychiatric researchers were more likely to come from

39. John P. Holt, Eleanore R. Wright, and Arthur O. Hecker, "Comparative Clinical Experience with Five Antidepressants," Am. J. Psychiatry, I960, 117, 533-38. See also English, "A Comparative Study of Antidepressants in Balanced Therapy."

40. Milton Greenblatt, George H. Grosser, and Henry Wechsler, "A Comparative Study of Selected Antidepressants and EST," Am. J. Psychiatry, I962, 119, I44-53; Norman Roulet et al., "Imipramine in Depression: A Controlled Study," Am. J. Psychiatry, I962, 119, 427-3 I; Milton Greenblatt, George H. Grosser, and Henry Wechsler, "Differential Response of Hospitalized Depressed Patients to Somatic Therapy," Am. J. Psychiatry, I964, 120, 935-43.

4I. John E. Overall et al., "Nosology of Depression and Differential Response to Drugs," J. Am. Med. Assoc., I966, 195, 946-48.

42. For a contemporary overview of changes in research over this time period, see H. Keith H. Brodie and Melvin Sabshin, "An Overview of Trends in Psychiatric Research: I963I972," Am. J. Psychiatry, I973, 130, I309-I8. 
academic medical centers and to participate in large collaborative research groups. ${ }^{43}$ Further, researchers had become well versed in the language of science as applied to medicine in their study design, their biochemical explanations for drug effects, and their use of statistics. ${ }^{44}$ Although occasional researchers presented case summaries in order to demonstrate the clinical effectiveness of a treatment regimen, many research groups by the I970s employed statisticians to help them with increasingly complex data analysis. ${ }^{45}$

But while psychiatric research was appearing to become more scientific, there were some research practices and assumptions that went unquestioned. First, pharmaceutical companies by this time period had begun a practice of designing their own research studies and analyzing their own statistics. ${ }^{46}$ Second, clinical trials on depressed patients more and more reinforced the circular definition of depression: depressed patients were those who could be shown to

43. The National Institute of Mental Health (NIMH) organized a large group to work on the problem of depression in the I970s. For contemporary explanations of the group, see Martin M. Katz and Gerald L. Klerman, "Introduction: Overview of the Clinical Studies Program," Am. J. Psychiatry, I979, 136, 49-5I; Martin M. Katz et al., "NIMH Clinical Research Branch Collaborative Program on the Psychobiology of Depression," Arch. Gen. Psychiatry, I979, 36, 765-7I. For a retrospective account of the group, see Morris B. Parloff and Irene Elkin, "The NIMH Treatment of Depression Collaborative Research Program," in History of Psychotherapy: A Century of Change, ed. Donald K. Freedheim (Washington, D.C.: American Psychological Association, I992), pp. $442-49$.

44. See for example A. Kessell, T. A. Pearce, and N. F. Holt, "A Controlled Study of Nortriptyline and Imipramine," Am. J. Psychiatry, I970, 126, 938-45; Arthur J. Prange et al., "Enhancement of Imipramine by Thyroid Stimulating Hormone: Clinical and Theoretical Implications," Am. J. Psychiatry, I970, 127, I9I-99; Karl Rickels et al., "Amitriptyline and Trimipramine in Neurotic Depressed Outpatients: A Collaborative Study," Am. J. Psychiatry, I970, 127, 208-18; Robert V. DeSilverio et al., "Perphenazine-Amitriptyline in Neurotic Depressed Outpatients: A Controlled Study," Am. J. Psychiatry, I974, 131, 25-30; Allen Raskin, "A Guide for Drug Use in Depressive Disorders," Am. J. Psychiatry, I974, 131, I 8 I -85 .

45. See for example Lino Covi et al., "Drug and Psychotherapy Interactions in Depression," Am. J. Psychiatry, I976, 133, 502-8. For an example of the use of case summary data, see James J. Cadden and Frederic F. Flach, "Differential Response to Treatment as a Function of the Changing Character of Depression," Am. J. Psychiatry, I970, 126 , IOI3-I6.

46. The first study I found that was sponsored (including study design and statistical analysis) by a pharmaceutical company (Geigy) was Abraham Heller, Rorry Zahourek, and H. G. Whittington, "Effectiveness of Antidepressant Drugs: A TripleBlind Study Comparing Imipramine, Desipramine, and Placebo," Am. J. Psychiatry, I97I, 127, I092-95. The current pharmaceutical industry role in clinical research is a subject of intense discussion and disagreement. See for example Healy, Let Them Eat Prozac. 
have responded to antidepressants. ${ }^{47}$ Investigators worked hard to make sure that they had a reasonably homogenous subject population and freely excluded patients with schizophrenia-type diagnoses. ${ }^{48}$ Further, some began to develop a rudimentary nosology of depressive types based on responses to medication. ${ }^{49}$

In this time period, women continued to be clearly predominant in clinical samples that were by then selected based on symptoms. Investigators seemed to expect that they would have greater numbers of women in their samples and did not comment on this other than to say that women were more depressed than men. Further, the fact that researchers had more women than men in their clinical trials appeared to be in and of itself further evidence that depression was more prevalent in women than in men. ${ }^{50}$ Researchers did not comment on the number of patients who had been excluded from clinical trials because of other disorders, such as alcoholism (which was-and is-diagnosed more frequently in men), although one investigator pointed out that the sex differences in prevalence of depression disappeared when male alcoholism was added to female depression in family illness studies. ${ }^{51}$

By the I970s, researchers generally stated that depression was more common in women than in men. Of course, this was a highly charged decade in which to be making claims about the high incidence of a psychiatric diagnosis in a group of women: the women's liberation movement of the I970s had particularly targeted psychiatry

47. See for example Helmut Beckmann and Frederick K. Goodwin, "Antidepressant Response to Tricyclics and Urinary MHPG in Unipolar Patients: Clinical Response to Imipramine or Amitriptyline," Arch. Gen. Psychiatry, I975, 32, I7-2 I; Patricia Neely Wold and Kirby Dwight, "Subtypes of Depression Identified by the KDS-3a: A Pilot Study," Am. J. Psychiatry, I979, 136, I4I5-I9.

48. John Feighner and his group used a preliminary criteria-based definition of depression in a study published in I972 on the effects of augmenting imipramine. John P. Feighner et al., "Hormonal Potentiation of Imipramine and ECT in Primary Depression," Am. J. Psychiatry, I972, 128, I230-38.

49. See for example Anthony LaPolla and Harry Jones, "Placebo-Control Evaluation of Desipramine in Depression," Am. J. Psychiatry, I970, 127, 335-38; Heller, Zahourek, and Whittington, "Effectiveness of Antidepressant Drugs."

50. See for example Alberto DiMascio et al., "Differential Symptom Reduction by Drugs and Psychotherapy in Acute Depression," Arch. Gen. Psychiatry, I979, 36, I450-56; Bruce J. Rounsaville, Brigitte A. Prusoff, and Nancy Padian, "The Course of Nonbipolar, Primary Major Depression: A Prospective I6-Month Study of Ambulatory Patients," J. Nerv. Ment. Dis., I980, 168, 406-I I.

5I. Joe Dorzab et al., "Depressive Disease: Familial Psychiatric Illness," Am. J. Psychiatry, I97I, 127, I I28-33. 
as a source of patriarchal social control. ${ }^{52}$ Social science researchers of the time took seriously the idea that there might be a number of factors that could explain women's apparent increased propensity to become depressed, including explanations of women's stressful social environments. ${ }^{53}$ Although some psychiatric researchers were clearly acting on older assumptions about women's nature and role in society when they described women's depression, others who were far more sympathetic to women also described the importance of treating women for depression. ${ }^{54}$

But despite increased inquiry about the role of sex in depression, by the I970s the supposition that depression was a disease of women had become entrenched to the point that studies that were done entirely on women were reported as studies on depression itself. For example, the influential team of Myrna Weissman and Gerald Klerman at Yale published extensively on a large-scale study of forty depressed women, but many of Weissman and Klerman's conclusions were explicitly generalized to include all patients who were depressed. ${ }^{55}$ Further, some of the articles from this study were published without anything in the title or abstract to indicate that women were the only subjects. ${ }^{56}$ The link between women patients

52. See for example Betty Friedan, The Feminine Mystique (New York: Dell Publishing, I963); Barbara Ehrenreich and Deirdre English, For Her Own Good: 150 Years of the Experts' Advice to Women (Garden City, N.Y.: Anchor Press, I978). Some contemporary feminist psychiatrists also engaged with the issues of sex, gender, and women's relationship to psychiatry in the past and present. See Anne M. Seiden, "Overview: Research on the Psychology of Women. I. Gender Differences and Sexual and Reproductive Life," Am. J. Psychiatry, I976, 133, 995-I007; Seiden, "Overview: Research on the Psychology of Women. II. Women in Families, Work, and Psychotherapy," Am. J. Psychiatry, I976, 133, I I I I-23.

53. See for example Walter R. Gove, "The Relationship between Sex Roles, Marital Status, and Mental Illness," Soc. Forces, I972, 51, 34-44; Lenore Radloff, "Sex Differences in Depression: The Effects of Occupation and Marital Status," Sex Roles, 1975, 1, 249-65.

54 . For a contemporary thoughtful commentary on women's social roles and their interactions with psychiatry, see Virginia Abernethy, "Cultural Perspectives on the Impact of Women's Changing Roles on Psychiatry," Am. J. Psychiatry, 1976, 133, 657-6I.

55. See for example Myrna M. Weissman, Gerald L. Klerman, and Eugene S. Paykel, "Clinical Evaluation of Hostility in Depression," Am. J. Psychiatry, I97I, 128, 26I-66; Gerald L. Klerman et al., "Treatment of Depression by Drugs and Psychotherapy," Am. J. Psychiatry, 1974, 131, I86-9I. Weissman and Klerman were by no means the only ones to study only women and then generalize to everyone. See also Eva Y. Deykin and Alberto DiMascio, "Relationship of Patient Background Characteristics to Efficacy of Pharmacotherapy in Depression," J. Nerv. Ment. Dis., I972, 155, 209-I 5.

56. Myrna M. Weissman and Gerald L. Klerman, "The Chronic Depressive in the Community: Unrecognized and Poorly Treated," Compr. Psychiatry, I977, 18, 523-32. The book that encapsulated Weissman's and Klerman's findings did explain that their studies were performed on women. Myrna M. Weissman and Eugene S. Paykel, The Depressed Woman: A Study of Social Relationships (Chicago: University of Chicago Press, I974). 
and a diagnosis of depression was quite specific, as research on depressive symptoms in schizophrenia (work in which Weissman collaborated) used much larger numbers of men in the clinical trials. ${ }^{57}$ Although all the researchers of this time period made assumptions about women consistent with their social and cultural context, a number of researchers, particularly Weissman, perceived research on depression to be of service to women. ${ }^{58}$

\section{THEORIES ABOUT DEPRESSION}

In the early I950s, psychiatrists occasionally described symptoms or diagnoses of depression, but these discussions tended to involve disagreement about the extent to which depression was a stand-alone problem and how different forms of depression could be classified. Eduard Ascher from the Henry Phipps Clinic at Johns Hopkins, for example, argued in 1952 that there were multiple ways in which depression could be divided, depending on how theorists understood its relationship to precipitating events or mania. ${ }^{59}$ Psychiatrists in Great Britain made much of a distinction between "endogenous" depression, a type of depression that seemed to come out of nowhere, and "exogenous" or "reactive" depression that arose in the context of a life stress. ${ }^{60}$ That distinction was less commonly invoked in the United States, although the labels "endogenous" and "reactive" sometimes appeared in clinical trials. More commonly, with the new medications introduced in the I950s and I960s, the issue of how to understand and classify depression became tied up with the idea of being able to predict which patients would respond to medication. While some authors approached the issue of differentiating forms of depression by observing the natural history of the illness, others looked to epidemiology for answers to this question. ${ }^{61}$

57. Brigitte A. Prusoff et al., "Treatment of Secondary Depression in Schizophrenia: A Double-Blind, Placebo-Controlled Trial of Amitriptyline Added to Perphenazine," Arch. Gen. Psychiatry, I979, 36, 569-75.

58. Myrna M. Weissman and Gerald L. Klerman, "Sex Differences and the Epidemiology of Depression," Arch. Gen. Psychiatry, I977, 34, 98-I I I.

59. Eduard Ascher, "A Criticism of the Concept of Neurotic Depression," Am. J. Psychiatry, I952, 108, 90I-8.

60. See David R. Hawkins and Joseph Mendels, "Sleep Disturbance in Depressive Syndromes," Am. J. Psychiatry, I966, 123, 682-700; Jackson, Melancholia and Depression, 2 I I-I9. 6I. See for example Robert A. Woodruff, Jr., George E. Murphy, and Marijan Herjanic, "The Natural History of Affective Disorders-I. Symptoms of 72 Patients at the Time of Index Hospital Admission," J. Psychiatr. Res., I967, 5, 255-63; Charlotte Silverman, "The Epidemiology of Depression-a Review," Am. J. Psychiatry, I968, 124, 883-9I. 
By the I960s and I970s, the most fruitful avenue of research for understanding depression seemed to be in looking at antidepressant medication and how medication effects could help explain the mechanism of depression.

In the early years of medication trials, the theoretical approach toward depressive symptoms that seemed to make the most sense was treatment by opposite (the hallmark of the traditional allopathic medicine treatment), and so stimulants appeared to hold the most promise for depression. A number of stimulants (including methylphenidate and even cocaine) were given to patients, with the idea that depressed patients needed to be stimulated. ${ }^{62}$ One of the first psychiatric medications used, iproniazid, was an anti-tuberculosis medication that was noted to cause euphoria in patients with TB. ${ }^{63}$ But as psychiatrists engaged more in treating depressive states, they constructed increasingly elaborate theories about why and how depressive states might occur.

Although psychiatric medications were originally given because their effects seemed to oppose the clinical presentation of the patients (i.e., euphoria of medication to counter depression), researchers by the I960s began to take this reasoning further to make inferences about what was happening in patients' brains before and with treatment based on observed effects of medication. In depression, what this meant was that researchers found (in animal models) that some of the so-called antidepressants had effects on serotonin and norepinephrine, two recently discovered neurotransmitters. Psychiatrists therefore inferred that, since medications that increased levels of these neurotransmitters caused euphoria (at least in animals), depression must be caused by a deficiency in these neurotransmitters.

While the reasoning about neurotransmitters could be somewhat abstract and difficult to apply on a clinical level, some researchers

62. See for example Frederick Lemere and James H. Lasater, "Deanol (Deaner) a New Cerebral Stimulant for the Treatment of Neurasthenia and Mild Depression: A Preliminary Report," Am. J. Psychiatry, I958, 114, 655-56; Ralph N. Wharton et al., "A Potential Clinical Use for Methylphenidate with Tricyclic Antidepressants," Am. J. Psychiatry, I97I, 127, I6I9-25; Robert M. Post, Joel Kotin, and Frederick K. Goodwin, "The Effects of Cocaine on Depressed Patients," Am. J. Psychiatry, I974, 131, 5I I-I 7.

63. After the apparent success of iproniazid, other researchers tried out other anti-tuberculosis medication to see if they would help with depressive states. See for example George E. Crane, "Cyloserine as an Antidepressant Agent," Am. J. Psychiatry, I959, 115, I025-26. 
were easily able to translate allopathic principles into drug effects on the brain. For example, T. R. Robie explained that iproniazid worked in depression by protecting serotonin in the brain: "Serotonin, allowed free activity in the brain, is perhaps the most energetic releaser of reserve power in the human machine, and this effect will overcome melancholia in a majority of cases within 2 to 4 weeks." ${ }^{\prime \prime}$ Joseph Schildkraut, a major researcher in brain physiology, explained this more scientifically in his often-cited 1965 review on the theory of depression that he called the "catecholamine hypothesis." Schildkraut said that the hypothesis came about because drugs that decrease norepinephrine cause sedation or depression in animals, whereas drugs that increase norepinephrine (including monoamine oxidase inhibitors and amphetamine) "are associated with behavioral stimulation or excitement and generally exert an antidepressant effect in man." 65 While Schildkraut cautioned that this theory could not account for all medication effects or all forms of depression, his hypothesis became (and continues to be) the working theory for depression. ${ }^{66}$ Although Schildkraut's hypothesis was much more technical than Robie's explanation, both reasoned backwards about the cause of depression from the effects of medication that seemed to work on depressive states (states that were themselves defined by medication effect). ${ }^{67}$

Although the direct stimulus for increased theorizing about depression was the increase in availability of somatic treatments of

64. T. R. Robie, "Marsilid in Depression," Am. J. Psychiatry, I958, 114, 936-37.

65. Joseph J. Schildkraut, "The Catecholamine Hypothesis of Affective Disorders: A Review of Supporting Evidence," Am. J. Psychiatry, I965, 122, 509-22. See also Joseph J. Schildkraut et al., "Norepinephrine Metabolism and Drugs Used in the Affective Disorders: A Possible Mechanism of Action," Am. J. Psychiatry, I967, 124, 600-8; Joseph J. Schildkraut, "Norepinephrine Metabolites as Biochemical Criteria for Classifying Depressive Disorders and Predicting Responses to Treatment: Preliminary Findings," Am. J. Psychiatry, I973, 130, 695-99.

66. A few researchers noted at the time that there were major biochemical problems with the catecholamine hypothesis. See for example David L. Dunner and Ronald R. Fieve, "Affective Disorder: Studies with Amine Precursors," Am. J. Psychiatry, i975, 132, I 80-83; Joe Mendels et al., "Amine Precursors and Depression," Arch. Gen. Psychiatry, I975, 32, 22-30.

67. A similar process of inferring backwards from drug effect occurred in schizophrenia. Researchers in the I960s and I970s concluded that, since chlorpromazine seemed to help in schizophrenia and since the medication reduced dopamine, schizophrenia is caused by abnormal dopamine levels. This hypothesis has been seriously questioned in recent years, however. See Robert E. McCullumsmith, Sarah M. Clinton, and James H. Meador-Woodruff, "Schizophrenia as a Disorder of Neuroplasticity," Int. Rev. Neurobiol., 2004, 59, I9-45. 
depression, not all theorists were committed to a strictly biological point of view. For example, one group used psychotropic medication to explore their "psychodynamic effects," particularly in dream analysis and markers for hostility (which, according to psychoanalytic theorists, turned inward in depression). ${ }^{68}$ Many prominent researchers used a combination of epidemiology, sociological assessments, and psychoanalytic and biological theories in order to try to explain depression and patients' responses to medication. ${ }^{69}$ For example, in 1974 Donald Klein, a leading researcher in psychiatry, made complex charts and graphs describing signs, symptoms, and etiologies of depression. In I975, University of Tennessee researcher Hagop Akiskal made a herculean effort to synthesize ten widely divergent ideas about how patients got to be depressed. ${ }^{70}$

One of the consistent assumptions by theorists of depression was that women were depressed more often than men. Not only did researchers and theorists not question this assumption, but they reasoned from the apparent predominance of women in treatment for depression that something in women could explain depression itself. $^{71}$ For example, Edward Klaiber and his group set out to measure activity of monoamine oxidase (MAO) in the plasma of depressed patients (on the theory that high $\mathrm{MAO}$ in the blood meant that high MAO in the brain was using up norepinephrine and therefore causing depression). Klaiber's group looked specifically at depressed women, estrogen augmentation, and MAO activity. The group found that MAO activity was higher in depressed womenthis meant (according to Schildkraut's catecholamine hypothesis) that the depressed women had less brain norepinephrine (which

68. Milton Kramer et al., "Drugs and Dreams III: The Effects of Imipramine on the Dreams of Depressed Patients," Am. J. Psychiatry, I968, 124, I385-92. See also Cadden and Flach, "Differential Response to Treatment as a Function of the Changing Character of Depression."

69. See for example Denis Hill, "Depression: Disease, Reaction, or Posture?," Am. J. Psychiatry, I968, 125, 445-57; Eugene S. Paykel et al., "Life Events and Depression: A Controlled Study," Arch. Gen. Psychiatry, I969, 21, 753-60; Wallace Wilkins, "Psychoanalytic and Behavioristic Approaches toward Depression: A Synthesis?," Am. J. Psychiatry, I97I, 128, 358-59.

70. Donald F. Klein, "Endogenomorphic Depression: A Conceptual and Terminological Revision," Arch. Gen. Psychiatry, I974, 31, 447-54; Hagop S. Akiskal and William T. McKinney, Jr., "Overview of Recent Research in Depression: Integration of Ten Conceptual Models into a Comprehensive Clinical Frame," Arch. Gen. Psychiatry, 1975, 32, 285-305.

7I. Although I focus here on biological themes, some psychiatrists saw the strong relationship between women and depression in terms of women's presumed dependence on social relationships. See for example Alfred S. Friedman, "Interaction of Drug Therapy with Marital Therapy in Depressive Patients," Arch. Gen. Psychiatry, I975, 32, 619-37. 
explained their depression). But despite the fact that there did not seem to be a relationship between MAO activity and estrogen, Klaiber's group still insisted on including hormones as part of the catecholamine hypothesis: "Mental depression is a component of the premenstrual tension syndrome. It is tempting to speculate, therefore, that the premenstrual tension syndrome and psychiatric states of mental depression are two points on a continuum separated by differences in elevation of MAO activity." ${ }^{2}$ Estrogen became inextricably tied to the catecholamine hypothesis (despite a lack of convincing evidence) because of researchers' assumptions that depression was something that tended to happen in women.

Although researchers continued to be interested in the role of estrogen in depression, one group in 1974 administered testosterone to five depressed men on the theory that "if being 'more female' worsens the patient's response to imipramine and if being male improves it (as well as lessening the risk for depression), then being 'more male' might further improve the response to imipramine." Instead, the researchers found that four of the men became paranoid; rather than interpret this as a failure, the group concluded that "It is tempting to say that by using a male hormone we converted the illness of four men from one typical of women to one typical of men." 73 Even in descriptions of depression in men, women's biology and the biology of depression became intertwined in theories

72. Edward L. Klaiber et al., "Effects of Estrogen Therapy on Plasma MAO Activity and EEG Driving Responses of Depressed Women," Am. J. Psychiatry, I972, 128, I492-98. Klaiber's group continued to believe that estrogen played some role in depression, and continued to perform clinical trials of estrogen in depression. See Edward L. Klaiber et al., "Estrogen Therapy for Severe Persistent Depressions in Women," Arch. Gen. Psychiatry, I979, 36, 550-54. Psychiatrists had been convinced for decades, despite the meager evidence in their published research, that estrogen was going to turn out to be a treatment for women (particularly post-menopausal women) with mental illness. See for example Herbert S. Ripley, Ephraim Shorr, and George N. Papanicolaou, "The Effect of Treatment of Depression in the Menopause with Estrogenic Hormone," Am. J. Psychiatry, I940, 96, 905-I3. For more historical discussion of assumptions about menopause and aging in women, see Lois Banner, In Full Flower: Aging Women, Power, and Sexuality (New York: Vintage Books, I992); S. E. Bell, "Changing Ideas: The Medicalization of Menopause," in The Meanings of Menopause: Historical, Medical, and Clinical Perspectives, ed. R. Formanek (Hillsdale, N.J.: Analytic Press, I990), pp. 43-63.

73. Ian C. Wilson, Arthur J. Prange, and Patricio P. Lara, "Methyltestosterone with Imipramine in Men: Conversion of Depression to Paranoid Reaction," Am. J. Psychiatry, I974, 131, 2I, 23. Wilson and his group refer to imipramine's greater effectiveness in men, but I have not found specific mention of this (other than in passing with no references) in the literature. 
about depression and led to further assumptions that depression was a women's disease. ${ }^{74}$

\section{SCALES AND CRITERIA}

Beginning in the I960s, some researchers began to tackle what they observed to be a particular problem in depression research: the shifting ideas about depression and a lack of consistency among clinical studies. As San Francisco neuropsychiatrist Martin Blinder explained in 1966 ,

the greatest problem is that the phenomena lumped together under the term "depression" are a mixed bag containing some essentially physiological disturbances; some symptom complexes with both physiological or psychic disturbances; some isolated symptoms which may reflect either a physiological or psychic disturbance; and some unconscious, habitual patterns of behavior which may repeatedly bring the patient to grief. ${ }^{75}$

Since there seemed to be no consensus in sight about possible etiologies of depression, some researchers turned instead to the question of how they could track response to treatment over time, particularly in patient symptoms. In the I960s, an increasing number of investigators developed tools for clinicians to measure patient symptoms and to evaluate changes in these symptoms over time, particularly with response to medications. But as more and more clinical trials proceeded that based their evidence on changes in symptoms, the disorder of depression seemed to be defined as a constellation of symptoms. Over the subsequent two decades, these symptoms were incorporated into the diagnostic criteria for depression and formalized in the 1980 DSM-III. ${ }^{76}$

While psychologists had produced a large number of assessment scales over the previous half century, psychiatrists in the I960s and

74. Researchers continued to ask questions about the relationship of depression to menopause, even when they could find no relationship. See for example George Winokur, "Depression in the Menopause," Am. J. Psychiatry, I973, 130, 92-93.

75. Martin G. Blinder, "The Pragmatic Classification of Depression," Am. J. Psychiatry, I966, 123, 26I.

76. Interestingly enough, the fact that the introduction of new treatments seemed to be driving a substantial increase in interest in theories about depression was not much acknowledged at the time. Many instead began to insist by the I960s that depression was an ancient illness but had been unsatisfactorily treated until recently. See for example Max L. Lurie and Harry M. Salzer, "Tranylcypromine (Parnate) in the Ambulatory Treatment of Depressed Patients," Am. J. Psychiatry, I961, 118, I 52-55. 
I970s articulated the need to produce new scales, this time to specifically measure psychiatric illness and response to medication. ${ }^{77}$ In the I960s, a number of rating scales were developed to measure progress in medication trials. The origins of these rating scales bear some further investigation, as the circumstances under which the rating scales were developed affected which symptoms were included in the scales. A good example of this is in the comparison between the Hamilton Depression Scale, developed by Max Hamilton in Great Britain and published in I960, and the Beck Depression Inventory, developed by Aaron Beck at the University of Pennsylvania and published in I96I.

The Hamilton Rating Scale for depression was developed in I960 on a patient population comprised entirely of men. Max Hamilton, a researcher at the University of Leeds, devised a rating scale in 1960 that assessed severity of depression and included symptoms such as agitation, gastrointestinal symptoms, other somatic symptoms, including hypochondriasis, and psychic and somatic anxiety. Only two or three of the items asked patients to respond to a question about how they felt, and there was more emphasis on bodily symptoms than on feeling states. The Hamilton scale emphasized observation of the patient (rather than self-reporting) and was to be completed by a trained staff person. ${ }^{78}$ Hamilton went back and reassessed his rating scale in 1967 with a larger population of patients, including a number of women. He concluded that his original scale worked well for the larger group of men, but that women scored significantly differently in some areas. ${ }^{79}$

In contrast, Aaron Beck, the University of Pennsylvania psychiatrist who went on to develop Cognitive Behavioral Therapy (CBT),

77. Some psychiatric researchers used components of the MMPI in their research but generally commented that this scale was not sensitive to changes with treatment over time. On the history of psychological assessment, see Roderick D. Buchanan, "The Development of the Minnesota Multiphasic Personality Inventory," J. Hist. Behav. Sci., I994, 30, I48-6I; Paul Davis Chapman, "Schools as Sorters: Testing and Tracking in California, I910-I925," J. Soc. Hist., I98I, 14, 70I-I7; Michael M. Sokal, ed., Psychological Testing and American Society, 1890-1930 (New Brunswick, N.J.: Rutgers University Press, 1987). On the growth of the influence of psychology in the post-World War II years, see Ellen Herman, The Romance of American Psychology: Political Culture in the Age of Experts (Berkeley: University of California Press, I995).

78. Max Hamilton, "A Rating Scale for Depression," J. Neurol. Neurosurg. Psychiatry, I960, 23, 56-62.

79. Max Hamilton, "Development of a Rating Scale for Primary Depressive Illness," Br. J. Soc. Clin. Psychology, I967, 6, 278-96. 
described a depression that had over ten items devoted to different feeling states. ${ }^{80}$ Not coincidentally, Beck's inventory was developed in a patient population that comprised over $60 \%$ women. Patients completed the assessment themselves and were asked to endorse statements (to varying degrees) about how they felt about themselves and their relationships. ${ }^{81}$ There were very few items about somatic symptoms in Beck's inventory; as would be expected, Beck's scale worked especially well to track improvement with CBT (as well as medication). Beck's scale was much more widely used than Hamilton's in the United States in subsequent decades, possibly because it did not require additional personnel in order to collect the scores, and possibly because its questions about feeling states matched most American psychiatrists' assumptions about depression. ${ }^{82}$

Both the Hamilton and Beck scales were explicitly designed to allow researchers to track items that were particularly likely to be affected by the treatment that was being studied. As Healy has pointed out, Hamilton's scale was particularly focused on physiological signs and symptoms that were likely to be produced by antidepressants that were being tested at the time of the scale's development. ${ }^{83}$ Researchers in the I960s and I970s frequently used Hamilton's scale to measure drug effects, but without attention to how men and women might score differently on the scale. Like the Hamilton scale, the Beck scale was also developed around a set of assumptions about depression: that feeling states could adequately capture core symptoms of depression. Beck's scale was subsequently adapted as a screening tool for depression in the general population, and his emphasis on feelings was also incorporated into the diagnostic criteria for depression in the I970s. But researchers and epidemiologists

80. Aaron T. Beck, Cognitive Therapy and the Emotional Disorders (New York: International Universities Press, I976).

8I. As several researchers pointed out at the time, some viewed self-assessment scales as less biased than observer scales because they assessed the patient's symptoms directly. See for example William W. K. Zung, "A Cross-Cultural Survey of Symptoms in Depression," Am. J. Psychiatry, 1969, 126, II6-2I.

82. A. T. Beck et al., "An Inventory for Measuring Depression," Arch. Gen. Psychiatry, I96I, 4, 56I-7I. Myron Sandifer and his group developed a rating scale in the I960s to try to differentiate endogenous and reactive depression. Like the Beck scale, Sandifer's scale included a number of thoughts and feelings, but it also included one item on "somatization." Sanifer's group developed and tested their scale on an entirely female ward. Myron G. Sandifer, Ian C. Wilson, and Linda Green, "The Two-Type Thesis of Depressive Disorders," Am. J. Psychiatry, I966, 123, 93-97.

83. Healy, The Antidepressant Era, pp. 98-Ioo. 
who used Beck's scale did not address the issue of how men at that time (or in the future) might respond to a screening tool that asked multiple questions about feeling states. ${ }^{84}$

Although some psychiatrists used rating scales to track treatment over time, others used response to medication itself as a way of classifying types of depression. ${ }^{85}$ Still others conducted elaborate factor analysis in order to assess which symptoms seemed to be most important in hospitalized depressed patients. Some investigators used elaborate statistical measures to ensure that the factors they identified in patients were in fact the most important symptoms to that group of patients. Allen Raskin, from the Psychopharmacology Research Branch at NIMH, and his group in the late I960s evaluated a very large number of patients in ten hospitals to determine the most important symptoms in depressed patients. In their study (which included 466 women and I 82 men), the following factors seemed to be most important in depression: "I) depressed mood, 2) feelings of guilt and worthlessness, 3) hostility, 4) anxiety-tension, 5) cognitive loss and subjective uncertainty, 6) interest and involvement in activities, 7) somatic complaints, 8) sleep disturbance, 9) retardation in speech and behavior, Io) bizarre thoughts and behavior, I I) excitement and I2) denial of illness. " 86 In determining that these factors were the most essential to describe depression, Raskin's group did not speculate on the effects of the demographics of his patient sample (particularly the substantially larger number of women). What Raskin and others engaged in similar analyses were trying to accomplish, however, was a scientific notion of depression.

Depression was not the only disorder treated or described by psychiatrists during this time period that was not particularly well defined. Many other diagnoses were somewhat vague, and leaders within the field were worried about how psychiatry would appear in comparison to other specialties in this regard. Robert Spitzer, the energetic architect of DSM-II, DSM-III, and DSM-IIIR, frequently expressed his concern that psychiatry appeared unscientific because there was very little agreement among psychiatrists

84. For an overview on constructions of masculinity over the twentieth century, see Michael S. Kimmel, Manhood in America: A Cultural History (New York: Free Press, 1996).

85. Horwitz, "Physiologic Responses as Prognostic Guides in the Use of Antidepressant Drugs."

86. Allen Raskin et al., "Replication of Factors of Psychopathology in Interview, Ward Behavior and Self-Report Ratings of Hospitalized Depressives," J. Nerv. Ment. Dis., I969, $148,87-98$, p. 87. 
about psychiatric diagnoses. Spitzer, with his colleagues in New York (at the New York Psychiatric Institute and Columbia University), as well as a large group of investigators at Washington University in St. Louis, worked on defining specific categories of illnesses in order to improve research and the scientific standing of psychiatry. $^{87}$

In the I970s, the psychiatrists in New York and St. Louis moved to formalize the disease categories in psychiatry and to update the vague language and inconsistent use of the second edition of the Diagnostic and Statistical Manual. ${ }^{88}$ These groups developed specific diagnostic criteria for diagnoses, and then focused a great deal of energy in determining whether these diagnostic sets would help psychiatrists agree more on the diagnosis of patients with similar symptoms. ${ }^{89}$ For depression, psychiatrists interested in assisting with classification looked at populations of patients (predominately women) who were in the hospital with what was commonly understood to be depression. The symptoms endorsed by these patients were then counted and analyzed to see which best characterized the population of patients. For the new classification system, etiology took a back seat to rigorous description; thus, the distinction between endogenous and exogenous depression did not matter if a patient met the criteria. As with the medication trials, patients with alcoholism or drug dependence were not included.

87. See for example John P. Feighner, "Nosology: A Voice for a Systematic Data-Oriented Approach," Am. J. Psychiatry, I979, 136, I I73-74. While many members of the profession accepted the idea that psychiatry needed an improved nosology by the I970s, some within (and without) the field strongly objected to the disease model of mental disorder implied by a classification scheme. See for example Thomas S. Szasz, "The Problem of Psychiatric Nosology: A Contribution to a Situational Analysis of Psychiatric Operations," Am. J. Psychiatry, I957, 114, 405-I3. Szasz would go on to make this critique even more strongly in subsequent years. Thomas S. Szasz, “The Myth of Mental Illness," Am. Psychol., I960, 15, I I3-i 8.

88. American Psychiatric Association, Diagnostic and Statistical Manual of Mental Disorders, 2nd ed. (Washington, D.C.: American Psychiatric Association, I968). DSM-II had represented a substantial departure from the first edition of DSM in I952. The American Psychiatric Association's Committee on Nomenclature and Statistics, headed by Spitzer, had authorized the I968 revision in order to bring the United States in line with psychiatric diagnoses used in the International Classification of Disease (ICD-8). Robert L. Spitzer and Paul T. Wilson, "A Guide to the American Psychiatric Association's New Diagnostic Nomenclature," Am. J. Psychiatry, I968, 124, I6I9-29.

89. Stuart A. Kirk and Herb Kutchins, The Selling of DSM: The Rhetoric of Science in Psychiatry (New York: Aldine de Gruyter, I992); Herb Kutchins and Stuart A. Kirk, Making Us Crazy: DSM, the Psychiatric Bible and the Creation of Mental Disorders (New York: Free Press, I997). 
In the early I970s, both the St. Louis group and the New York group developed similar sets of research criteria to formalize the category of depression (as well as other mental disorders), which eventually led to the DSM-III category. In general, both of these sets included the obligatory symptom of depressed mood, plus an additional set of symptoms and a minimum time frame of a month. The criteria from the New York group also included the proviso that patients needed either to have sought help for their condition or to have been noticed by others to need help..$^{90}$ The DSM-III criteria for depression were similar to these research criteria, but the number of symptoms required to make the diagnosis was reduced, as well as the amount of time the symptoms needed to be present. $^{91}$

By I980, with the publication of DSM-III, depression seemed to be a clearly defined entity. ${ }^{92}$ The Epidemiological Catchment Area (ECA) Study, a large mental health and illness epidemiological study performed in the early I980s, used DSM criteria to screen the general population to estimate the prevalence of psychiatric disease. ${ }^{93}$ Within the ECA study, as well as others since that time, the diagnosis of depression based on symptoms was not only used without question, but researchers also used the presence of symptoms of depression in order to screen the population for untreated cases of depression. Researchers and epidemiologists assumed that it was valid to use criteria that had been determined in a hospitalized population in order to test the public for untreated or undiagnosed

90. John P. Feighner et al., "Diagnostic Criteria for Use in Psychiatric Research," Arch. Gen. Psychiatry, I972, 26, 57-63; Robert L. Spitzer, Jean Endicott, and Eli Robins, "Research Diagnostic Criteria: Rationale and Reliability," Arch. Gen. Psychiatry, I978, 35, 773-82; Jean Endicott and Robert L. Spitzer, "Use of the Research Diagnostic Criteria and the Schedule for Affective Disorders and Schizophrenia to Study Affective Disorders," Am. J. Psychiatry, I979, 136, 52-56.

9I. American Psychiatric Association, DSM-III, pp. 205-24.

92. Although the mood descriptor of "irritability" was included in DSM-III, it disappeared for adults by the next edition (DSM-IIIR). Irritability was noted to be a possible symptom for children and adolescents. It is not clear why this descriptor was eliminated. Most clinicians who treat men now agree that irritability is a prominent feature of depression in men. American Psychiatric Association, Diagnostic and Statistical Manual of Mental Disorders, 3 rd rev. ed. (Washington, D.C.: American Psychiatric Press, I987), pp. 2I3-33.

93. Darrel A. Regier et al., "One-Month Prevalence of Mental Disorders in the United States: Based on Five Epidemiologic Catchment Area Sites," Arch. Gen. Psychiatry, I988, 45, 977-86; Lee N. Robins and Darrel A. Regier, eds., Psychiatric Disorders in America: The Epidemiologic Catchment Area Study (New York: Free Press, I99I). 
illness. ${ }^{94}$ Further, ECA and other researchers did not ask questions about what in particular was being measured with DSM criteria. Perhaps not surprisingly, when researchers used the criteria for depression (which had been developed in a patient population that was generally two-thirds or more women), they found that more women than men endorsed the symptoms (at a ratio of about two to one). Most psychiatrists and epidemiologists have assumed that this finding, because it had taken place in the context of using scientific criteria in a large sample population, constituted the final scientific proof of women's greater propensity to depression. ${ }^{95}$ Further, many researchers since then have concluded that there must be something in women's biology that predisposes them to depression. In the last twenty years, the supposition that depression is a disease that occurs primarily in women has become dogma, and many contemporary researchers have assumed that women's hormonal systems have a key role in the etiology of depression. ${ }^{96}$

\section{CONCLUSION}

In I974, Jonathan Cole summarized the tremendous variety of treatments and possibilities for depressed patients in his editorial connected to a special issue of the American Journal of Psychiatry on treatments of depression. Cole enthused that "From the psychiatrist's viewpoint only, depression is an exceedingly satisfactory disease. It is comforting, in this day of existential doubt and psychosocial malaise, to have an illness that is quite treatable and that is recognized by almost everyone as a real illness demanding real treatment." 97 In the decades following Cole's comments on the positive aspects of diagnosing and treating depression, the illness would

94. Johns Hopkins researchers in the I970s had investigated this issue in a small community sample and found that the presence of symptoms was not the best way to differentiate clinical and community samples. See Thomas J. Craig and Pearl A. Van Natta, "Presence and Persistence of Depressive Symptoms in Patient and Community Populations," Am. J. Psychiatry, I976, 133, I426-29. See also Frederick S. Mendelsohn, Gladys Egri, and Bruce P. Dohrenwend, "Diagnosis of Nonpatients in the General Community," Am. J. Psychiatry, I978, 135, I I63-67.

95. See for example Weissman and Klerman, "Sex Differences and the Epidemiology of Depression."

96. See for example S. G. Kornstein et al., "Gender Differences in Chronic Major and Double Depression," J. Affect. Disord., 2000, 60, I-I I; Mary V. Seeman, "Psychopathology in Women and Men: Focus on Female Hormones," Am. J. Psychiatry, I997, 154, I64I-47; Kenneth S. Kendler et al., "The Prediction of Major Depression in Women: Toward an Integrated Etiologic Model," Am. J. Psychiatry, I993, 150, I I39-48.

97. Jonathan O. Cole, "Depression," Am. J. Psychiatry, I974, 131, 204-5. 
assume a larger and larger role in the medical literature. By the I980s, depression was frequently described as the "common cold" of mental illness, and family practitioners were encouraged to diagnose and treat it in their patients. ${ }^{98}$ In a very short period of time, depression had been transformed from a murky set of signs and symptoms to a clear, specific, and treatable diagnostic entity. But in the process, a number of assumptions (particularly about women) were buried within the "scientific" basis of the disease.

First, psychiatrists assumed from the I950s onward that women were depressed more than men. Researchers studied hospitalized depressed women, counted their symptoms, and then used them to define a category of depression. The question of whether women were depressed more than men was never raised. Second, the vast majority of studies on psychiatric medication between the I950s and the I980s included substantially more women than men. ${ }^{99}$ This is particularly problematic since so much of the current theory around the etiology of depression was inferred backwards from the presumed mechanism of action of the antidepressant medication. Thus the connection between women and depression has been a closed circle: researchers have assumed that women are depressed more than men, which means that women have been preferentially diagnosed, treated, and theorized about, leading to further conclusions that women are depressed more than men. At the present time, the assumed connection between women and depression is fueling a great deal of research on the presumed biological mechanism of depression that is frequently assumed to somehow be connected to women's unique biology.

As I have shown with the example of depression, what gets called scientific truth is very much contingent on social, cultural, and

98. In I974, Aaron Beck adopted his Depression Inventory as a screening tool to address what he identified as the major problem of undiagnosed depression (with a high risk of morbidity and possible risk of suicide). Aaron T. Beck and Alice Beamesderfer, "Assessment of Depression: The Depression Inventory," Mod. Probl. Pharmacopsychiatry, I974, 7, I5 I-69. On family physicians and the diagnosis and treatment of depression, see for example Michael J. Garvey, "Biochemistry and Treatment Strategies for Depression," J. Fam. Pract., I980, 11, 2 I 5-I9.

99. Both Joel Braslow and Jack Pressman pointed out that women were more often subjected to (or provided with, depending on the interpretation) psychiatric interventions in the past than men. Joel Braslow, Mental Ills and Bodily Cures: Psychiatric Treatment in the First Half of the Twentieth Century (Berkeley: University of California Press, I997); Jack D. Pressman, Last Resort: Psychosurgery and the Limits of Medicine (New York: Cambridge University Press, I998). 
professional factors. Certainly there have been in the past, and continue to be, real people suffering from real mental illnesses. But having said that, it is not at all clear-even with the trappings of modern science that psychiatry has acquired in the past few decades-how to sort out the roles of biology and culture in constructing a particular patient's or society's definition or experience of illness. ${ }^{100}$ In this article, I have focused on the ways in which psychiatric theories and practices have embedded within them assumptions about gender and illness. The complex relationships among psychiatric theory and ethnicity, race, class, and age still require further investigation. ${ }^{101}$ The details of the construction of the modern diagnosis of depression have implications for further study of the history of psychiatry, as well as the current practice and research in psychiatry and the approach of patients toward psychiatric theory and therapies. How a diagnosis is made matters-both to psychiatrists, as they engage in research and treatment, and to patients, as they explain their experiences and negotiate with treatment providers. Depression has become a widely discussed-and treated-illness and warrants further historical attention.

IOO. Edward Shorter has argued against the social constructivists in the history of mental illness by pointing out that there is true, biologically based mental illness. See Edward Shorter, A History of Psychiatry: From the Era of the Asylum to the Age of Prozac (New York: John Wiley \& Sons, I997). While I would agree that there is real mental illness, I would also argue that what counts and is experienced as illness by a patient and by others is very much socially constructed. On changing patterns of interpreting symptoms in a cultural context, see Elaine Showalter, Hystories: Hysterical Epidemics and Modern Media (New York: Columbia University Press, I997).

IOI. There are relatively few primary sources on racial differences in psychiatry theory and practice. See for example Allen Raskin and Thomas H. Crook, "Antidepressants in Black and White Inpatients: Differential Response to a Controlled Trial of Chlorpromazine and Imipramine," Arch. Gen. Psychiatry, I975, 32, 643-49. 